\title{
Putting Severity of Punishment Back in the Deterrence Package
}

\author{
Silvia M. Mendes \\ Department of Political Science \\ Binghamton University (SUNY) \\ Binghamton, NY 13902 USA \\ \& \\ Department of Management \& Public Administration \\ University of Minho \\ 4710 Braga, PORTUGAL
}

Michael D. McDonald

Department of Political Science

Binghamton University (SUNY)

Binghamton, NY 13902 USA 


\begin{abstract}
Studies of criminal deterrence usually show an effect of certainty of punishment but often fail to find an effect of severity. This is a serious threat to the theoretical underpinnings of deterrence theory. Through both a survey of 39 analyses in 33 published studies and our own reanalysis of an often-used data set, we show the problem rests not with the theory but with the analysis of the theory. Finding no severity effect can be traced to "unbundling the theoretical package" when moving from the theory to the statistical models used to represent the theory.
\end{abstract}




\section{Introduction}

The economic approach to crime is anchored on the theory of deterrence. With roots in late eighteenth century Classicism, deterrence theory holds that increasing the certainty of punishment, in the form of a higher probability of arrest and conviction, or increasing the severity of punishment, in the form of longer sentences, will raise the prospective costs of committing a crime. With a higher expected cost, crime is deterred. To register a dissuasive effect in the potential criminal's mind, conviction must follow arrest and punishment must follow conviction. If criminals go unpunished, arresting and convicting become empty threats and could hardly weigh much against the gain to be won for committing the crime.

Despite this reasoning, it has become commonplace in the literature on criminal deterrence to downplay the effect of the severity of punishment. Empirical testing proves generally consistent with the theory in regard to the effects that higher probabilities of arrest and conviction have on the crime rate. As for the other half of deterrence theory, severity is often found to be of little consequence. After considering the results from a series of deterrence studies from the 1970s, Anne Witte $(1983,320)$ remarked that "Changes in the probabilities of conviction and imprisonment have a greater effect on crime rates than do changes in expected sentence length ...

," a comment that Scott Decker and Carol Kohfeld (1990, 3) later endorsed, "A large group of studies have shown that measures of certainty are inversely related to the level of offenses. The same relationship for severity has not been found."

More recently, under a study commissioned by the UK Home Office, Andrew von Hirsch and his colleagues (von Hirsch et al., 1999) surveyed and analysed the criminal deterrence literature. Their main purpose was to address the reported efficacy of marginal deterrent strategies, especially severity effects. They began with reference to research in the 1970s and offered observations similar to Witte's, “...most earlier studies have suggested that certainty has substantially the stronger general deterrent effect," compared to severity (p. 5). Then, after reviewing research completed over the past 20 years, von Hirsch et al. remarked that "evidence 
concerning severity effects is less impressive" (p.47). They saw "scant evidence" and only "modest negative correlations between some severity variables and crime rates, albeit ones that seldom achieve statistical significance." (p. 47) They concluded by asking: "What might account for severity's uncertain and seemingly limited effects" (p. 47-8)? Our purpose is to supply an answer to this question.

Our answer is that the dubious findings regarding the inconsistent effect of the severity component of deterrence theory are a consequence of theoretical slippage when moving from the verbal theoretical statement to the statistical representation of that statement. Our purpose is to demonstrate that the failure to include any of the deterrence theory components "unbundles the theoretical package". For this reason, we argue that the empirical ambiguity with respect to sentence severity arises because sometimes the empirical formulation of deterrence theory fails to keep the theoretical package intact. In particular, statistical models that isolate the components through the use of separate, additive elements do not account for the expected cost calculation as specified in the theory. Sentence length does not work independently of the probability of arrest and conviction. Rather, all three elements operate in combination. One logical implication of the null findings on severity of punishment is to suggest that it falsifies deterrence theory and therefore does not matter whether jurisdictions punish criminals they arrest and convict. This, we suggest, is not credible. “...neither certainty nor severity of punishment can substitute for the other... any deterrent impact of certainty depends on the level of severity. No doubt, severity by itself cannot replace certainty. But the reverse holds equally true." (van den Haag, 1975, 115). Models that do not reflect the combination of all deterrence elements fail to translate the theory and are likely to fall short of finding a significant effect for all of the components. In brief, our idea is to put severity of punishment back into the deterrence package.

We develop the argument and evidence in three steps. First, we work through the translation of the theory into a statistical model. Second, we review the existing literature in terms of the elements that have been implicitly or explicitly specified in the empirical analyses of 
deterrence theory. Third, we test our proposition using Thomas Pogue's data set (1983) and reestimate alternative versions of Scott Decker and Carol Kohfeld's (1990) model, which they applied to these data and found no severity effect. We find, in the literature and in our own empirical analysis, that once punishment is correctly accounted for in a model, the severity of punishment has a significant negative effect on crime and does indeed matter as deterrence theory tells us.

\section{Deterrence Theory and Its Statistical Representation}

The late 1960s marked a revival of the Classical school idea of criminals as rational beings, in contrast to the idea of criminals as persons suffering from psychological and societal neuroses. Scholars such as William Chambliss (1966), Jack Gibbs (1968), and Charles Tittle (1969) reframed deterrence logic within the context of criminological and sociological theories of deviance. About the same time, Gary Becker (1968) extended the reawakened human capital theory of economists to include, in the language of economics, the supply and control of crimes. Together, these efforts inspired social scientists with a new way to study criminal behavior and spurred a large number of theoretical and empirical studies.

\section{Theory}

Becker's formalization of deterrence theory has clearly withstood the test of time. He lays out the principal components of the theory, with an eye toward the certainty and the severity of punishment (Becker, 1968, 178). According to his model:

$$
O=O(p, f, u)
$$

The average number of offenses, $O$, is a function of the average probability of being convicted $(p)$, average punishment $(f)$, and a set of average socio-economic forces $(u)$. The first two elements, $p$ and $f$, are the core components of deterrence theory-i.e., the certainty of punishment and the severity of punishment. ${ }^{1}$ Potential criminals face a choice, and they opt to commit the crime if the 
expected gain exceeds the expected cost. An increase in either the certainty or the severity of punishment, while the other is held constant at a nonzero value, will reduce the expected utility associated with the crime.

$$
\begin{aligned}
& \text { "Practically all the diverse theories agree, however, that when } \\
& \text { other variables are held constant, an increase in a person's } \\
& \text { probability of conviction or punishment if convicted would } \\
& \text { generally decrease ... the number of offenses he commits" } \\
& \text { (Becker, 1968, 176). }
\end{aligned}
$$

Numerous empirical studies have attempted to translate deterrence theory into a statistical representation and test its veracity. As stated above, this body of literature has produced ambiguous results in regard to the effect of the different components of deterrence theory. Most studies find evidence in support of a deterrent effect of an increase in the certainty of punishment. However, less than half of the studies have found the same to be true of the severity of punishment. As a consequence, the more recent literature has tended to favor the certainty of punishment over the severity of punishment as a deterrent measure for reducing crime (von Hirsch et al., 1999).

Deterrence theory is about punishing criminal activity. Therefore, the expected cost is the probability of being punished, reflected in arrest and conviction rates, operating in conjunction with the severity of punishment. That is:

Expected Cost, Punishment $=f\left(p_{1}\right.$ Arrests, $p_{2}$ Convictions, Average Sentence $)$.

As a matter to be investigated empirically, potential criminals are supposed to look to their environment to form their subjective probabilities in accordance with the objective arrest rates, conviction rates of those arrested, and average sentence of those convicted. The hypothesized calculation in the potential criminal's mind is: 
Expected Cost, Punishment $=$ Arrest Rate $*$ Conviction Rate $\mid$ Arrest $*$ Average Sentence.

If the arrest rate is 40 percent, the conviction rate for those arrested is 50 percent, and the average sentence served for the crime is 10 years, then prospective criminals calculate that they can expect to spend two years in prison (i.e., $.4 \times .5 \times 10=2$ ). If any one of the three elements reduces to zero, as is an implied possibility when one says the severity of punishment does not matter, then the expected cost itself reduces to zero. There is no cost associated with the crime.

Deterrence, therefore, must be considered as a package with three components: arrests, convictions, and sentences. ${ }^{2}$ The failure to find an effect of one of these elements "unbundles" the theory and undermines its credibility. If the threat of a sentence is not backed up with effective or real sentences, then how can the deterrent effect of the threat endure? If potential criminals are rational agents as the theory assumes, they would soon perceive that criminal behavior would be going unpunished. This would substantially reduce the cost of committing crime in their eyes. Therefore, disregarding the sentencing component of deterrence is not acceptable. It says the theory works part-way, but there is no part-way. Deterrence theory stands or falls as a whole.

\section{Statistical Representation}

The problem may not be with the theory itself but, rather, with the translation of the verbal theoretical statement into a statistical representation of that statement. Indeed, we maintain that this has often been the problem. As a package, the elements are interrelated and conditional upon each other. Conviction depends on arrests and sentences depend on conviction. Accordingly, these components must be appropriately incorporated into a statistical model, and the proper way to do this is to ensure the interdependency among the components. When severity is included as an element independent of arrests and convictions, the model is not telling the whole story.

What is the whole story in the form of a statistical model? A helpful way to answer this is to return to the arrest rates, conviction rates given arrests, and the average sentence for a particular crime. Expressed in their fractional forms, we have: 
Expected Cost, Punishment $=\frac{\text { Arrests }}{\text { Offenses }} * \frac{\text { Convictions }}{\text { Arrests }} * \frac{\text { Total Length of Sentences Served }}{\text { Convictions }}$.

The first thing to notice is that the three components operate interdependently. As we have been saying, they are multiplicative elements, not additive. In statistical models, this would be called a three-way interaction. The second thing to notice is that when the multiplication is carried through, several elements cancel. That is,

$$
\text { Expected Cost, Punishment }=\frac{\text { Arrests }}{\text { Offenses }} * \frac{\text { Convictions }}{\text { Arrests- }} * \frac{\text { Total Length of Sentences Served }}{\text { Convictions }} .
$$

This reduces to:

$$
\text { Expected Cost, Punishment }=\frac{\text { Total Length of Sentences Served }}{\text { Offenses }}
$$

which is to say in a formula what deterrence theory says in words: the expected cost is the amount of time the potential criminal could expect to spend in prison. In a linear statistical model, the formulation maintains that crime rates will vary inversely with the expected cost, and thus:

$$
\text { Crime Rate }=\alpha+\beta \frac{\text { Total Length of Sentences Served }}{\text { Offenses }}+\varepsilon
$$

Alternatively, those formulations that use the certainty and severity measures as additive terms are not testing the theoretical proposition, so they are not necessarily expected to yield deterrent effects. At least we should not be surprised if they do not. The additive linear specification of deterrence theory unavoidably isolates these components, as the following equation shows:

$$
\text { Crime Rate }=\beta_{0}+\beta_{1} \text { Arrest Rate }+\beta_{2} \text { Conv Rate }+\beta_{3} \text { Avg Sentence }+\varepsilon \text {. }
$$

If $\beta_{3}$ is indistinguishable from zero, one might be tempted to infer that only arrests and convictions have deterrent effects and that the length of sentences does not matter. To say that, however, is to leave a huge hole in deterrence theory logic, so big a hole as to falsify the theory. 
But, of course, rejecting deterrence theory on the basis of the results from this linear equation does not follow because in this equation sentences are taken to be an independent matter. To see why this is not a falsifying result, we can reverse the process and go from the equation to the words. The words are that imprisoning persons independent of whether they have been convicted of a crime does not deter crimes. Deterrence theory certainly would agree with that proposition. If a criminal (in)justice system punishes persons regardless of whether they have been convicted, then the calculating prospective criminal might as well go ahead and commit the crime. He or she is liable to be punished regardless.

Isaac Ehrlich (1967, cited in Becker 1968, 178) was among the first to offer an empirical test of Becker's formal model in the late 1960s and early 1970s using sophisticated regression analysis. ${ }^{3}$ A close look at his early, published work reveals that Ehrlich (1973) constructed a theoretically more comprehensive market model, but on the deterrence core elements of Becker's original formulation he always used and sometimes insisted on a multiplicative specification.

“... [T] he theory identifies the basic deterrence variables ... to include the unconditional probabilities of conviction and execution which are functionally dependent via a multiplicative relationship ...” (Ehrlich, 1977, 747, emphasis in the original).

Ehrlich's formulation of the deterrence elements, however, gives a first impression that the statistical model takes an additive form. His log-linear functional form is:

$$
\ln (\text { Crime Rate })=\beta_{0}+\beta_{1} \ln P_{a}+\beta_{2} \ln P_{c}+\beta_{3} \ln \text { Sentence Severity }+\mu .
$$

where $P_{a}$ is the probability of arrest, $P_{c}$ is the probability of conviction given arrest, and Sentence Severity is a measure of the typical sentence a convicted criminal serves for a given crime. Of course, removing the logarithms shows this formulation has implicitly built in the interdependency among the three elements. That is:

$$
\text { Crime Rate }=\beta_{0}{ }^{\prime} *\left(P_{a}^{\beta_{1}}\right) *\left(P_{c}^{\beta_{2}}\right) *\left(\text { Sentence Severity }{ }^{\beta_{3}}\right) * \mu^{\prime} \text {. }
$$


Despite the early warnings about the proper statistical form of the deterrence components, some authors have implicitly and explicitly challenged the log-linear function. Sometimes the warnings have been overlooked or ignored. One alternative is to portray the crime rate as semilogarithmic (e.g. Swimmer, 1974a; 1974b; Hoenack \& Weiler, 1980) or logistic (e.g., Decker \& Kohfeld, 1990), where the crime rate outcomes are a result of additive, level differences in the deterrence elements. The semi-logarithmic model can take one of two forms, log-lin or lin-log, only one of which is additive. The lin-log model (Hoenack \& Weiler, 1980) is multiplicative:

Crime rate $=\beta_{0}+\beta_{1} \ln P_{a}+\beta_{2} \ln P_{c}+\beta_{3} \ln$ Sentence Severity $+\mu$.

or

$e^{\text {Crime rate }}=\beta_{0}{ }^{*} *\left(P_{a}^{\beta_{1}}\right) *\left(P_{c}^{\beta_{2}}\right) *\left(\right.$ Sentence Severity $\left.{ }^{\beta_{3}}\right) * \mu^{\prime}$.

The log-lin model (Swimmer, 1974a; 1974b) is additive:

$$
\ln (\text { Crime Rate })=\beta_{0}+\beta_{1} \text { Arrest Rate }+\beta_{2} \text { Conv Rate }+\beta_{3} \text { Avg Sentence }+\lambda .
$$

The logistic form (Decker \& Kohfeld, 1990) is also additive:

$$
\ln \{\text { Crime Rate } / 1-\text { Crime Rate }\}=\beta_{0}+\beta_{1} \text { Arrest Rate }+\beta_{2} \text { Conv Rate }+\beta_{3} \text { Avg Sentence }+\gamma \text {. }
$$

In last two cases, the interdependency among the elements is lost. In the lin-log form, the elements on the right-hand side add together to produce a result. For the log-lin form, the re-transformed right-hand side becomes:

$$
\operatorname{Pr}(\text { Crime })=1 /\left(1+e^{\beta_{0}+\beta_{1} \text { Arrest Rate }+\beta_{2} \text { Conv Rate }+\beta_{3} \text { Avg Sentence }+\emptyset}\right) ;
$$

for the logistic form, it becomes: ${ }^{4}$

$$
\text { Odds }(\text { Crime })=\beta_{0} e^{\beta_{1} \text { Arrest Rate }+\beta_{2} \text { Conv Rate }+\beta_{3} \text { Avg Sentence }+\delta} .
$$

Theoretical elaboration of deterrence studies to incorporate private demand for protection, public demand for law enforcement, and supply of offenses, as in Ehrlich's $(1973 ; 1996)$ general market model, are widely appreciated. There has been commentary, and in policy studies an explicit debate however about the statistical formulation of the core deterrence components. In sociological approaches to studying crime rates, Harold Grasmick \& Steven McLaughlin (1978) 
criticized Matthew Silberman (1976) for using the language of interactive effects for certainty and severity but failing to follow through and use interactions in his analysis. This has not been of much moment, however, inasmuch as most studies in the sociological tradition have focused attention on the certainty component alone. In psychological and social psychological work on perceptual deterrence, Grasmick writing with George Bryjak (1980), as well Mark Stafford et al. (1986), re-raised the argument expressed in the late 60 s in favor of certainty and severity operating interactively.

Of the scores of individual-level studies of perceptual deterrence some make reference to Grasmick \& Bryjak (1980) but few take the interactive relationship seriously enough to use interactions in their statistical estimations. In part, this is quite likely due to the fact that perceptual studies have focused their attention on the certainty component. Paternoster (1987, 188), asserts that "Within a few years, those working in the area came to understand that if the deterrence process works, it does so solely through perceived certainty", and citing Jensen et al. (1978), he continues "Given doubts about the importance of the severity and celerity of punishments...there is justification for focusing deterrence on the perceived certainty of punishment. Thus, research testing the perceived-certainty deterrence hypothesis flourished ...while research on perceived severity waned (italics in the original)". More than a decade later, after reviewing perceptual deterrence studies, von Hirsch et al. (1999) saw the state of perceptual evidence in much the same way. They wrote, "longitudinal studies have not considered severity effects much ...," and experimental studies "do not systematically address the effects of severity of formal criminal sanctions" (von Hirsch et al. 1999, 35).

Research that has focused on criminal deterrence as a policy theory and policy instrument, principally those studies grounded in the economic approach, have raised the issue of certainty and severity's interactive operation in ways that confront one another head on. That is, the interaction has been explicitly debated in policy-focused deterrence research. In particular, Bowers \& Pierce (1975), Passell \& Taylor (1977), and Layson (1985) estimate equations to see whether the 
deterrence hypothesis can be considered robust in the sense that it finds support regardless of the functional form. Bowers \& Pierce, as well as Passell \& Taylor, arrive at dubious results for equation forms other than Ehrlich's log-linear formulation. They conclude that deterrence reasoning itself is in doubt. When Layson finds that the alternatives provide evidence supporting all three deterrence components, he concludes: "The deterrence findings are clearly robust with respect to the choice of functional forms" (Layson, 1985, 86).

The problem with these arguments is that deterrence theory gives us the functional form; it does not leave it as a matter of choice for the analyst. It surely matters, relatively speaking, that the log-linear form outperforms the others, as it does in all three studies. If that relative outperformance were not the case, we would have to search deterrence theory or an alternative theory to explain why the theoretically proper functional form does not work as well as others. On the other hand, it is of no consequence to a deterrence inference that equation forms not derived from the theoretical specification perform poorly in the sense of being statistically insignificant. Nor does it matter that they perform well in the sense of being significant.

In sum, we should not expect to find consistent deterrent effects of the certainty and the severity measures under all equation forms. Only when the multiplicative relationship among these measures is respected, either directly or indirectly in the lin-log or log-linear form, is Becker's theoretical statement faithfully reflected by a statistical model.

\section{Crime and the Severity of Punishment in the Literature}

Table 1 organizes the results of a literature survey we conducted of the studies that estimate the effects of both the certainty and severity of punishment. Data on punishment severity are difficult to obtain, and, as a consequence, most deterrence studies are not able to draw a full and clear distinction between these elements. Still, we have located 33 studies, 10 of which use an additive formulation, 18 of which treat the deterrence components as multiplicative, and five of which estimate both additive and multiplicative functional forms. This provides us with 39 
analyses that estimate both components of deterrence. Twenty-eight of these studies conform to our expectations: when an additive model is used, there is almost always no severity effect, and when a multiplicative model is used, there most often is a severity effect.

[Table 1 about here]

Apparently, it is not the precise form (e.g. linear, log-lin, etc.) of the additive model that fails to uncover a severity effect. Almost every additive model we have reviewed fails in this respect. Seven studies use additive models in a linear form. These include: Bean \& Cushing (1971), Bowers \& Pierce (1975), Forst (1976), Passell \& Taylor (1977), Klein et al. (1978), Layson (1985), and Trumbull (1989). As shown in Table 1, every one but Layson and Trumbull comes up short on the severity of punishment. Four studies, Swimmer (1974a; 1974b), Vandaele (1978), and Layson (1985) adopt a semi-logarithmic additive form. They too, except for Layson, fail to find a significant effect for the severity of punishment. Finally, Witte (1980), Myers (1983), Decker \& Kohfeld (1990), as well as Kim et al. (1993), use additive models of a tobit, logistic, or event history (Weibull) form and also find no severity effect.

From Ehrlich's early analysis onward, the multiplicative models have usually taken a loglinear form. They most often have found a severity effect; 15 do and nine do not. The exceptions that we were able to locate are: Sjoquist (1973), Passell \& Taylor (1977), Nagin (1978a), Holtman \& Yap (1978), Klein et al. (1978), Kleck (1979), Hoenack \& Weiler-lin-log model (1980), Sesnowitz \& Hexter (1982), and Willis (1983).

From Table 1, it is fitting to argue that finding a severity effect depends on choosing a multiplicative versus an additive model. Given these results in the literature, we reason that it is inadmissible to judge the severity of punishment as an ambiguous deterrent policy tool. Most of the ambiguity appears to rest on doubts that analysts have about which model is the proper statistical formulation of deterrence theory. The evidence often fails when the translation fails. The expected evidence follows from the theory when the translation follows from the theory. 


\section{An Empirical Investigation}

The variety of studies reported in the literature differ in so many respects that a more compelling approach may well be to apply both the additive and multiplicative models to the same data, control for relevant forces in the same way, and thereby test whether deterrence theory performs as expected. Building on the early arguments of the proper functional form to test deterrence theory, we ask: When the additive and multiplicative formulations are applied, ceteris paribus, does the severity of punishment perform as deterrence theory predicts? In particular, does the evidence show an effect when the statistical model keeps the theoretical package intact and fail to show an effect when severity is treated as an element independent of the probability of punishment? To explore these questions, we replicate Decker \& Kohfeld's (1990) additive model used to analyze crime rates in the U.S. states and extend it by applying the multiplicative form. Surely, one could argue with the non-deterrence elements included and excluded from the Decker \& Kohfeld model. For instance, Ehrlich's (1973) theoretical extensions of the Beckerian model to create a theoretically comprehensive market model are not much apparent in the Decker \& Kohfeld model. Involving ourselves in these extensions would entail further changes in the model, and this would not allow us to concentrate directly on the operation of the deterrence variables. With this in mind, we want to stay as close to the Decker \& Kohfeld model as we can.

\section{Data}

Decker \& Kohfeld use Pogue's 1970 data, Deterrent effects of imprisonment and arrests in the United States 1960-1970 (ICPSR File 7973). ${ }^{5}$ These data cover 31 or 32 states, depending on the crime category - 31 states for robbery, 31 states for larceny, and 32 states for burglary. ${ }^{6}$ Descriptive statistics and variable definitions are presented in Table 2.

[Table 2 about here]

In 1970 , there were on average 100 robberies and approximately nine times as many burglaries and eight times as many larcenies for every 100,000 persons. The average clearance 
rate is also substantially higher for robbery than for each of the two property crimes $-34 \%$ as compared to $20 \%$ for burglary and $12 \%$ for larceny. The probability of conviction can be described as either convictions per offense or convictions given arrests. In either case, the probability measure is higher for robbery than for the two property crimes. About one third of the robberies are cleared by arrest and close to one fifth (19\%) of those arrested for robbery are convicted. Only about $20 \%$ of burglaries are cleared, and of those arrested a mere $5 \%$ are convicted. But even those relatively small numbers for burglaries are better than the $12 \%$ clearance rate and the $5 \%$ conviction rate for larceny. We can also see that the typical median time served is much higher for robbery, approximately 34 months, than for either larceny or burglary, about 19-21 months. None of this is surprising, given that violent crime is more vigorously pursued and more harshly punished than are property crimes.

It is worth noting that the expected cost of these three different types of crime varies considerably. The average expected cost for robbery is 1.82 months, compared to a modest .194 months (about six days) for burglary and an even more modest .096 months (about three days) for larceny. A part of the difference between the expected costs is due to the longer average sentence for robbery, but much of the difference rests with the low conviction rate for burglary and larceny. Indeed, based on these aggregate numbers, one could speculate that the robbery crime rate is lower than the burglary and larceny rates because, as deterrence theory would predict, the average expected cost for robbery is 10 to 20 times higher than for the other types of crime.

\section{Models}

Decker \& Kohfeld (1990) analyzed three crime rates in the form of a log odds (logit) transformation and tested the effects of two measures of the certainty of punishment - the clearance rate and the probability of imprisonment - and one measure of the severity of punishment - the median time served in prison. Their model is:

$$
\ln (\text { C rate } / 1-\text { C rate })=\beta_{0}+\beta_{1} \text { Clear }+\beta_{2} \text { Conv } \mid \text { Offn }+\beta_{3} \text { Time Served }+\beta_{4} \text { Nonwhite }+\beta_{5} \text { Unemploy }+e,
$$


where all variables are defined in Table 2. This equation keeps the deterrence package partially intact, because their conviction variable expresses convictions as a percentage of all offenses. This is the variable one arrives at by combining the arrest rate with the conviction rate given arrests:

$$
\text { Prob }(\text { Punishment })=\frac{\text { Arrests }}{\text { Offenses }} * \frac{\text { Convictions }}{\text { Arrests }}=\frac{\text { Convictions }}{\text { Offenses }}
$$

Decker \& Kohfeld find significant negative effects of the certainty of punishment on the crime rates, via the probability of conviction, for all three crimes. They also find that the clearance rate has a deterrent effect in the case of robbery. However, they fail to find evidence of a deterrent effect of the length of sentence. Based on these results, they suggest that the severity of punishment is not an effective policy tool for reducing crime.

We extend the Decker \& Kohfeld model by putting all of the deterrent theory components back into the package. We do this, first, by staying close to the Decker \& Kohfeld model and substituting the expected cost measure, median time served/offenses, for their additive median time served. This model, Alternative 1, takes the form:

$$
\ln (\text { C rate } / 1-\text { C rate })=\beta_{0}+\beta_{1} \text { Clear }+\beta_{2} \text { Conv } \mid \text { Offn }+\beta_{3} \text { ExpCost }+\beta_{4} \text { Nonwhite }+\beta_{5} \text { Unemploy }+e .
$$

Because we think the full statement of deterrence theory is translated by having only the expected cost term on the right-hand side, we also estimate a second equation, Alternative 2:

$$
\ln (\text { C rate } / 1-\text { C rate })=\beta_{0}+\beta_{1} \text { ExpCost }+\beta_{2} \text { Nonwhite }+\beta_{3} \text { Unemploy }+e .
$$

Finally, we explore the log-linear multiplicative formulation as suggested by Ehrlich and others and contrast it with semi-logarithmic equations. The log-linear equation in this form is:

$$
\ln (\text { C rate })=\beta_{0}+\beta_{1} \ln (\text { Clear })+\beta_{2} \ln (\text { Conv } \mid \text { Arr })+\beta_{3} \ln (\text { Time })+\beta_{4} \ln (\text { Nonwhite })+\beta_{5} \ln (\text { Unemploy })+e .
$$

We hypothesize that once the statistical model is written and estimated with the deterrence package intact, the severity of punishment will show an effect, contrary to the conclusion of Decker \& Kohfeld. This should hold true for the linear multiplicative alternative to the Decker \& Kohfeld model as well as the log-linear model. 


\section{Findings}

Table 3 shows the results of the analysis of the certainty and severity of punishment on the robbery, burglary, and larceny crime rates according to the Decker \& Kohfeld equation and our two alternative equations. Column 1 , for each type of crime, presents the results of our replication of Decker \& Kohfeld's (1990) analysis plus their two control variables, the percentage of the state population that is nonwhite and the state unemployment rate. Column 2 replaces their additive median time served variable with a variable representing the expected cost. Column 3 reduces the model to crime rates as a function of the expected cost plus their two control variables.

[Table 3 about here]

Decker \& Kohfeld conclude from the results shown in column 1 for each crime that the severity of punishment is negligible since the median time served is insignificant for all three crimes. The certainty of punishment, through the probability of conviction, has a significant negative impact on all three crimes, and the clearance rate produces a deterrent effect only in the case of robbery.

The results of our first alternative, shown in column 2 for each type of crime, reveal that when the expected cost is used as a deterrent measure, the severity of punishment does have an effect on the robbery and burglary crime rates. Except for Conv $\mid O f f n$, which falls to insignificance with the introduction of the ExpCost variable, the remaining results are similar to those of the Decker \& Kohfeld estimation. In addition, in moving from the original Decker \& Kohfeld model to this alternative specification, we improve the overall fit, as adduced from either the adjusted $\mathrm{R}^{2}$ or the standard error of the estimate $\left(\mathrm{s}_{\mathrm{e}}\right)$.

The respective column 3's show the results of our second alternative. When estimating the model with the ExpCost as the sole deterrent variable, it is significant across all three crime categories, as expected. This supports our hypothesis that the expected cost of punishment reflects the entire deterrence argument. 
Figure 1 traces the predicted probabilities based on the model that uses the expected cost alone and under the conditions of holding Nonwhite at $10 \%$ and Unemploy at 5\%, values close to their means. At very low levels of the expected cost, on the order of expecting to spend three to six days in prison, the burglary and larceny crime rates are much higher than the robbery crime rate. Those two rates, relative to robbery, drop precipitously as the expected cost rises. This follows, of course, from the larger negative expected cost coefficients associated with burglary and larceny, compared to that of robbery. By the point where the expected cost is one half month or higher, there is not much that distinguishes rates of one type of crime from those of another type. This indicates, if only tentatively, that a criminal justice system might aim its sights on having the expected cost for property crimes run at one half to three quarters of a month.

[Figure 1 about here]

Critics might contend that our evidence is a mere artifact. The total number of criminal offenses is the key component of the dependent variable. Our measure of the expected cost, unlike the Decker \& Kohfeld additive severity measure, has offenses built into it and, therefore, could introduce spuriousness (Nagin, 1978b, 97-8; Eide, 1994, 125). In other words, perhaps the statistical strength we report for expected cost comes from building offenses into expected cost (expected $\operatorname{cost}=$ median time served/offenses). To check this possibility, we have taken the precaution of re-estimating all the equations in Table 3, with the inverse of offenses, 1/Offn, included on the right-hand side. ${ }^{7}$

[Table 4 about here]

The consequence of including $1 / O f f n$ does reveal that there is reason to worry about spurious effects of the deterrent elements. However, that worry has little or nothing to do with the expected cost effect. With $1 / O f f n$ controlled for, and with expected cost in the equation, we find that the arrest and conviction variables fall to statistical insignificance for all three types of crime. More than that, with $1 / O f f n$ controlled for, the single best model, as judged by having the highest adjusted $\mathrm{R}^{2}$ and the lowest standard error of estimate $\left(\mathrm{s}_{\mathrm{e}}\right)$, is the equation with expected cost 
standing alone to represent deterrence. Once potential spuriousness is taken into account, the evidence is entirely consistent with deterrence theory expectations. ${ }^{8}$

Our final empirical step is to estimate a log-lin, lin-log, and log-linear specification of the Decker \& Kohfeld (1990) model. We have three purposes. First, we want to check the robustness of our results with respect to our hypothesis that deterrence is a package. Second, we want to allow for the possibility that the deterrence elements carry different weights when it comes to deterring crimes (see endnote 2). Recall that the lin-log and log-linear forms preserve the three-way interdependency among arrests, convictions, and sentence length, and, therefore, it should show that the severity of punishment has an effect on crime rates. Unlike the three-way multiplicative term in the logit-linear formulation, the lin-log and log-linear models allow each of the three deterrence components to have different functional effects-i.e., to take on different exponential values. The possibility of different exponents is an empirical recognition that each component might carry a weight different from one another when it comes to deterring crimes. In the logitlinear, as well as in any model that creates the combination through a simple multiplication of the components, the exponent for each component is assumed to be the same value, 1.0. Third, we want to show that we should not expect to find evidence for deterrence theory when we use the lin$\log$ model because the interdependency is not present.

Table 5 reports the results of the estimation of these three models for all three crime types. In the case of the lin-log model, shown in the first column for each crime, we find an effect of the certainty of punishment through the probability of imprisonment for all three crimes and the clearance rate for robbery and larceny. We also find a significant effect of the severity of punishment on the robbery and burglary crime rates. As for the log-lin results, in the second column of each crime type, we find evidence of an effect of certainty of punishment. However, the severity measure just barely makes statistical significance and only in the case of robbery. ${ }^{9}$

[Table 5 about here] 
With respect to the log-linear results in the third column for each crime type, the two certainty components show theoretically consistent and statistically significant negative effects for all three crime categories. On the question of the severity of punishment, there are also theoretically consistent and statistically significant negative impacts for robbery and burglary. In the case of larceny, the estimated effect is positive, small, and unreliable. So far as we can tell, the severity effect for larceny is nonexistent, essentially zero. Is this because there is in fact no effect or is it because there is such small variation across states in the overall expected cost for larceny? We cannot be sure. We do have firm evidence, however, that for robbery and burglary, crimes for which the variation in expected cost is two to 15 times larger than that of larceny (see Table 2), the effect of the severity of punishment matters. This attests to our argument that the severity component of the deterrence package does carry weight when it comes to deterring crimes.

\section{Conclusion}

Deterrence is a theory. To see what it will produce, it is necessary to consider the theoretical recipe as something more than a list of ingredients. According to the theory, deterring criminal acts requires combining the probability of arrest, the probability of conviction given arrest, and a punishment of some severity following conviction. The combination of these three components creates an expected cost for committing a criminal act. Each of the three components is necessary; no one component acting alone is sufficient.

Gary Becker's theoretical specification of deterrence and the words of early sociologists do combine the components. Over the years, however, the empirical literature on deterrence theory has produced ambiguous results in regard to the effectiveness of the severity component of deterrence theory. Many empirical investigations report evidence to support the deterrent effect of an increase in the certainty of punishment but report no deterrent effect of the severity of punishment. Accepting these results for what they clearly imply-i.e., the severity of punishment

does not matter - the criminal justice system risks being misinformed about the value of punishing criminal behavior. In this case, deterrence theory would lose all credible theoretical force because 
the theory tells us that the probability of arrest and conviction is of limited value when the threat of punishment is not backed up with actual punishment.

We find that published empirical studies that fail to find a significant impact of the severity of punishment do not effectively translate the theory. It is not much of a surprise, then, that those studies cast doubt on whether deterrence theory works as it is supposed to work. On the other hand, models that combine the probability of punishment with the severity of punishment to form the expected cost as an interdependent multiplicative element, as the theory specifies, report evidence consistent with deterrence theory expectations. Furthermore, we show, through the use of Pogue's data for the U.S. states and through a re-estimation of the Decker \& Kohfeld (1990) model in three different ways, that deterrence theory works as a package and often fails when the package is "unbundled".

We conclude that deterrence must be treated as a package composed of three elements: arrests, convictions, and punishment. When this is the case, the severity of punishment does indeed represent an important role in implementing that package.*

* We are grateful to the ICPSR and the University of Michigan center for Political Studies for making available the Pogue data. We would also like to thank Greg Pogarsky for having taken the time to read and make helpful comment on this work. Mendes is particularly grateful to the University of Minho and the Fundação para a Ciência e Tecnologia for financial support while on leave at SUNY-Binghamton. 


\section{References}

Becker, Gary S. (1968). Crime and punishment: An economic approach. Journal of Political Economy, 78, 2, 169-217.

Bowers, William J. \& Pierce, Glenn L. (1975). The illusion of deterrence in Isaac Ehrlich's research on capital punishment. The Yale Law Journal, 85, 2, 187-208.

Bean, Frank D. \& Cushing, Robert G. (1971). Criminal homicide, punishment, and deterrence: Methodological and substantive reconsiderations. Social Science Quarterly, 52, 2, 277-89.

Chambliss, William. (1966). The deterrent influence of punishment. Crime \& Delinquency, 12, January, 70-5.

Chauncey, Robert. (1975). Deterrence: Certainty, severity, and skyjacking. Criminology, 12, 4, 447-73.

Decker, Scott \& Kohfeld, Carol W. (1990). Certainty, severity, and the probability of crime: A logistic analysis. Policy Studies Journal 19, 1, 2-21.

Ehrlich, Isaac. (1996). Crime, punishment, and the market for offenses. Journal of Economic Perspectives, 10, 1, 43-67.

Ehrlich, Isaac. (1977). Capital punishment and deterrence: Some further thoughts and additional evidence. Journal of Political Economy, 85, 4, 741-88.

Ehrlich, Isaac. (1975). The deterrent effect of capital punishment: A question of life and death. American Economic Review, 65, 3, 397-417.

Ehrlich, Isaac. (1973). Participation in illegitimate activities: A theoretical and empirical investigation. Journal of Political Economy, 81, 3, 521-65.

Ehrlich, Isaac. (1967). The supply of illegitimate activities. Unpublished manuscript, Columbia University, New York.

Eide, Erling. (1994). Economics of crime: Deterrence and the rational offender. Amsterdam: North Holland.

Forst, Brian. 1976. Participation in illegitimate activities: Further empirical findings. Policy Analysis, 2, 3, 477-92.

Frant, Howard, Berry, Frances Stokes, \& Berry, William. (1991). Specifying a model of state policy innovation. American Political Science Review, 85, 2, 571-80.

Gibbs, Jack P. (1968). Crime, punishment and deterrence. Social Science Quarterly, 48, 4, 515-30.

Gibbs, Jack P. (1975). Crime, punishment and deterrence. N.Y.: Elsevier.

Grasmick, Harold G. \& McLaughlin Steven. (1978). Deterrence and social control. American Sociological Review, 43, 2, 272-78. 
Grasmick, Harold G. \& Bryjak, George J. (1980). The deterrent effect of perceived severity of punishment. Social Forces, 59, 2, 471-91.

Grasmick, Harold G. \& Bursik, Robert J. (1990). Conscience, significant others, and rational choice: Extending the deterrence model. Law \& Society, 24, 3, 837-61.

Gray, Louis N. \& Martin, J. David. (1969). Punishment and deterrence: Another analysis. Social Science Quarterly, 50, 2, 389-95.

Hoenack, Stephen A. \& Weiler, William C. (1980). A structural model of murder behavior and the criminal justice system. American Economic Journal, 70, 3, 327-41.

Holtmann, A. G. \& Yap, L. (1978). Does punishment pay? Public Finance, 33, 1-2, 90-7.

Jarrell, Stephen \& Howsen, Roy M. (1990). Transient crowding and crime: The more 'strangers' in an area, the more crime except for murder, assault, and rape. American Journal of Economics and Sociology, 49, 4, 484-94.

Jensen, Gary F., Gibbs, Jack. P., \& Erickson, Maynard. (1978). Perceived risk of punishment and self-reported delinquency. Social Forces, 57, September, 57-78.

Kim, Il-joong, Benson, Bruce L., Rasmussen, David W., \& Zuehlke, Thomas W. (1993). An economic analysis of recidivism among drug offenders. Southern Economic Journal, 60, 1, $169-83$.

Kleck, Gary. (1979). Capital punishment, gun ownership, and homicide. American Journal of Sociology, 84, 4, 882-910.

Klein, Lawrence R., Forst, Brian, \& Filatov, Victor. 1978. The deterrent effect of capital punishment: An assessment of the elements. In Alfred Blumstein, Jacqueline Cohen, and Daniel Nagin (Eds.), Deterrence and incapacitation: Estimating the effects of criminal sanctions on crime rates (pp. 336-60). Washington, D.C.: National Academy of Sciences.

Layson, Stephen K. (1985). Homicide and deterrence: A reexamination of the United States timeseries evidence. Southern Economic Journal, 52, July, 68-89.

Logan, Charles H. (1972). General deterrent effects of imprisonment. Social Forces, 51, 1, 64-73.

Myers, Samuel L. (1983). Estimating the economic model of crime: Employment versus punishment effects. The Quarterly Journal of Economics, 98, 1, 157-66.

Myers, Samuel L. (1980). Why are crimes underreported? What is the crime rate? Does it really matter? Social Science Quarterly, 61, 1, 23-43.

Nagin, Daniel S. \& Pogarsky, Gregory. (2000). Integrating celerity, impulsivity, and extralegal sanction threats into a model of general deterrence: Theory and evidence. Paper presented at the annual meeting of the American Society of Criminology, held in San Francisco.

Nagin, Daniel S. (1978a). Crime rates, sanction levels, and constraints on prison population. Law \& Society Review, 12, 3, 341-66. 
Nagin, Daniel S. (1978b). General deterrence: A review of the general evidence. In Alfred Blumstein, Jacqueline Cohen, and Daniel Nagin (Eds.), Deterrence and incapacitation: Estimating the effects of criminal sanctions on crime rates (pp. 95-139). Washington, D.C.: National Academy of Sciences.

Paternoster, Raymond. (1987). The deterrent effect of the perceived certainty and severity of punishment, Justice Quarterly, 4, 2, 173-217.

Passell, Peter \& Taylor, John B. (1977). The deterrent effect of capital punishment: Another view. The American Economic Review, 67, 3, 445-51.

Phillips, Llad \& Votey, Harold. (1975). Crime control in California. Journal of Legal Studies, 4, 2, 327-49.

Pogue, Thomas F. (1983). The crime prevention effects of arrests and imprisonment: evidence from multiple cross-section analyses, NIJ Report.

Sesnowitz, Michael L. \& Hexter, Lawrence J. (1982). Economic determinants of theft: some empirical results. Public Finance Quarterly, 10, 4, 489-98.

Silberman, Matthew. (1976). Toward a theory of criminal deterrence. American Sociological Review, 41, June, 442-61.

Sjoquist, David. (1973). Property crime and economic behavior: Some empirical results. American Economic Review, 63, 3, 439-46.

Stafford, Mark C., Gray, Louis N., Ward, David A. (1986). Modeling the deterrent effects of punishment. Social Psychology Quarterly 49, 4, 338-47.

Swimmer, Eugene. (1974a). Measurement of the effectiveness of urban law enforcement: A simultaneous approach. Southern Economic Journal, 40, 4, 618-30.

Swimmer, Eugene. (1974b). The relationship of police and crime: Some methodological and empirical results. Criminology, 12, 3, 292-314.

Tittle, Charles R. (1969). Crime rates and legal sanctions. Social Problems, 16, 4, 409-23.

Tittle, Charles R.(1980). Sanctions and social deviance the question of deterrence. N.Y.: Praeger.

Trumbull, William N. (1989). Estimations of the economic model of crime using aggregate and individual level data. Southern Economic Journal, 56, October, 423-39.

van den Haag, Ernest. (1975). Punishing criminals concerning a very old and painful question. N.Y.: Basic Books.

Vandaele, Walter. (1978). Participation in illegitimate activities: Ehrlich revisited. In Alfred Blumstein, Jacqueline Cohen, and Daniel Nagin (Eds.), Deterrence and incapacitation: Estimating the effects of criminal sanctions on crime rates (pp. 270-335). Washington, D.C.: National Academy of Sciences. 
von Hirsch, Andrew, Bottoms, Anthony E., Burney, Elizabeth, Wickström, P-O. (1999). Criminal deterrence and sentence severity. Oxford, UK: Hart.

Willis, K. G. (1983). Spatial variations in crime in England and Wales: Testing an economic model. Regional Studies, 17, 4, 261-72.

Witte, Ann Dryden. (1980). Estimating the economic model of crime with individual data. Quarterly Journal of Economics, 94, February, 57-84.

Witte, Ann Dryden. (1983). Economic theories. In Sanford H. Kalish (Ed.), Encyclopedia of crime and justice, ed., vol 1 (pp. 316-22). New York: Free Press.

Wolpin, Kenneth I. (1978a). An economic analysis of crime and punishment in England and Wales. Journal of Political Economy, 86, 5, 815-40.

Wolpin, Kenneth I. (1978b). Capital punishment and homicide in England: A summary of results. American Economic Review Papers and Proceedings of the $90^{\text {th }}$ Annual Meeting of the American Economic Association, 68, 2, 422-27.

Wolpin, Kenneth I. (1980). A time series-cross sectional analysis of international variation in crime and punishment. Review of Economics and Statistics, 62, 3, 417-23.

Wong, Yue-Chim Richard. (1995). An economic analysis of the crime rate in England and Wales, 1857-92. Economica, 62, 246, 235-46. 
Table 1: Survey of the Literature, Effects of Certainty \& Severity of Punishment

\begin{tabular}{|c|c|c|c|}
\hline Author (Year) & Functional Form & $\begin{array}{l}\text { Significant Effect } \\
\text { of the Certainty } \\
\text { of Punishment }\end{array}$ & $\begin{array}{c}\text { Significant Effect } \\
\text { of the Severity of } \\
\text { Punishment }\end{array}$ \\
\hline \multicolumn{4}{|l|}{ Additive } \\
\hline Bean \& Cushing (1971) & Linear & & \\
\hline Swimmer (1974a) & Log-lin & & \\
\hline Swimmer (1974b)* & Log-lin & & \\
\hline Bowers \& Pierce (1975) & Linear & not reported & \\
\hline Forst (1976) & Linear & & \\
\hline Passell \& Taylor (1977) & Linear & $\checkmark$ & \\
\hline Klein et al. (1978) & Linear & $\checkmark$ & \\
\hline Vandaele (1978) & Log-lin & $\checkmark$ & \\
\hline Witte (1980) & Tobit & & \\
\hline Myers (1983) & Logistic & & \\
\hline Layson (1985) & Log-lin \& Linear & $\checkmark$ & $\checkmark$ \\
\hline Trumbull (1989) & Linear & $\checkmark$ & $\checkmark$ \\
\hline Decker \&Kohfeld (1990) & Logistic & $\checkmark$ & \\
\hline Jarrell \& Howsen (1990) & Tobit & $\checkmark$ & \\
\hline Kim et al. (1993) & Event History & $\checkmark$ & \\
\hline \multicolumn{4}{|l|}{ Multiplicative } \\
\hline Gray \& Martin (1969) & Linear Multiplicative & $\checkmark$ & $\checkmark$ \\
\hline Ehrlich (1973) & Log-linear & $\checkmark$ & $\checkmark$ \\
\hline Sjoquist (1973) & Log-linear & $\checkmark$ & \\
\hline Bowers \& Pierce (1975) & Log-linear & not reported & $\checkmark$ \\
\hline Ehrlich (1975) & Log-linear & $\checkmark$ & $\checkmark$ \\
\hline Phillips \& Votey (1975) & Log-linear & $\checkmark$ & $\checkmark$ \\
\hline Ehrlich (1977) & Log-linear & $\checkmark$ & $\checkmark$ \\
\hline Passell \& Taylor (1977) & Log-linear & $\checkmark$ & \\
\hline Nagin (1978a) & Log-linear & & \\
\hline Holtman \&Yap (1978) & Log-linear & $\checkmark$ & \\
\hline Klein et al. (1978) & Log-linear & $\checkmark$ & \\
\hline Wolpin (1978a) & Log-linear & $\checkmark$ & $\checkmark$ \\
\hline Wolpin (1978b) & Log-linear & $\checkmark$ & $\checkmark$ \\
\hline Vandaele (1978) & Log-linear & $\checkmark$ & $\checkmark$ \\
\hline Kleck (1979) & Log-linear & & \\
\hline Wolpin (1980) & Log-linear & $\checkmark$ & $\checkmark$ \\
\hline Hoenack \& Weiler (1980) & Log-linear \& Lin-log & $\checkmark$ & $\checkmark$ \\
\hline Myers (1980) & Log-linear & $\checkmark$ & $\checkmark$ \\
\hline Sesnowitz \& Hexter (1982) & Log-linear & $\checkmark$ & \\
\hline Willis (1983) & Log-linear & $\checkmark$ & \\
\hline Layson (1985) & Log-linear & $\checkmark$ & $\checkmark$ \\
\hline Stafford et al. (1986) & Log-linear & $\checkmark$ & $\checkmark$ \\
\hline
\end{tabular}


Wong (1995)

Log-linear

$\checkmark$

$\checkmark$

Note: A checkmark denotes a significant effect for more than half of the cases at the .05 level with a one-tailed test.

All studies test for the certainty and severity of punishment. *Swimmer's (1974b) interaction term does not allow us to measure the expected cost of punishment for it excludes the probability of arrest given the commission of a crime. 
Table 2: Variables, Definitions, and Descriptive Statistics

\begin{tabular}{|c|c|c|c|c|c|}
\hline Variable & Variable Definition & Mean & $\begin{array}{l}\text { Std. } \\
\text { Dev. }\end{array}$ & $\begin{array}{c}\text { Minimu } \\
m\end{array}$ & $\begin{array}{l}\text { Maxim } \\
\text { um }\end{array}$ \\
\hline \multicolumn{6}{|l|}{ Robbery } \\
\hline Robb & $\begin{array}{l}\text { The number of robberies per } 100,000 \text { persons known to police } \\
\text { in } 1970\end{array}$ & 100.059 & 99.872 & 6.400 & 442.100 \\
\hline RbClear & The percentage of reported robberies cleared by arrest in 1970 & 33.512 & 8.037 & 19.000 & 50.600 \\
\hline RbConv|Arr & $\begin{array}{l}\text { The percentage of convictions given arrests for robbery in } \\
1970\end{array}$ & 18.885 & 11.496 & 3.852 & 55.488 \\
\hline $\mathrm{RbConv|Off}$ & $\begin{array}{l}\text { The percentage of persons committed to state prisons in } 1970 \\
\text { for robbery as a proportion of known offenses for that crime in } \\
1970\end{array}$ & 6.646 & 5.315 & .940 & 28.077 \\
\hline RbTime & $\begin{array}{l}\text { The median time served in months before first release by } \\
\text { persons committed to state prisons for robbery and released in } \\
1970\end{array}$ & 34.273 & 19.786 & 13.000 & 120.000 \\
\hline RbExpCost & $\begin{array}{l}\text { Multiplicative term representing the expected cost for } \\
\text { committing a robbery in } 1970\end{array}$ & 1.819 & 1.043 & .330 & 3.936 \\
\hline \multicolumn{6}{|l|}{ Burglary } \\
\hline Burg & $\begin{array}{l}\text { The number of burglaries per 100,000 persons known to police } \\
\text { in } 1970\end{array}$ & 914.194 & 374.134 & 286.200 & 1751.500 \\
\hline BgClear & $\begin{array}{l}\text { The percentage of reported burglaries cleared by arrest in } \\
1970\end{array}$ & 19.746 & 3.767 & 12.700 & 28.200 \\
\hline BgConv|Arr & $\begin{array}{l}\text { The percentage of convictions given arrests for burglary in } \\
1970\end{array}$ & 5.452 & 3.344 & .807 & 14.596 \\
\hline$\overline{\text { BgConv|Off }}$ & $\begin{array}{l}\text { The percentage of persons committed to state prisons in } 1970 \\
\text { for burglary as a proportion of known offenses for that crime } \\
\text { in } 1970\end{array}$ & 1.088 & .688 & .150 & 2.890 \\
\hline BgTime & $\begin{array}{l}\text { The median time served in months before first release by } \\
\text { persons committed to state prisons for burglary and released in } \\
1970\end{array}$ & 20.907 & 17.664 & 7.500 & 112.286 \\
\hline BgExpCost & $\begin{array}{l}\text { Multiplicative term representing the expected cost of } \\
\text { committing a burglary in } 1970\end{array}$ & .194 & .132 & .030 & .609 \\
\hline \multicolumn{6}{|l|}{ Larceny } \\
\hline Larc & $\begin{array}{l}\text { The number of larcenies per } 100,000 \text { persons known to police } \\
\text { in } 1970\end{array}$ & 777.824 & 305.440 & 254.600 & 1388.600 \\
\hline LrClear & The percentage of reported larcenies cleared by arrest in 1970 & 12.247 & 4.169 & 7.500 & 27.500 \\
\hline LrConv|Arr & $\begin{array}{l}\text { The percentage of convictions given arrests for larceny in } \\
1970\end{array}$ & 5.523 & 4.904 & .912 & 23.646 \\
\hline LrConv|Off & $\begin{array}{l}\text { The percentage of persons committed to state prisons in } 1970 \\
\text { for larceny as a proportion of known offenses for that crime in } \\
1970\end{array}$ & .624 & .468 & .100 & 1.939 \\
\hline
\end{tabular}




\begin{tabular}{|c|c|c|c|c|c|}
\hline LrTime & $\begin{array}{l}\text { The median time served in months before first release by } \\
\text { persons committed to state prisons for larceny and released in } \\
1970\end{array}$ & 18.766 & 17.671 & 6.375 & 109.500 \\
\hline LrExpCost & $\begin{array}{l}\text { Multiplicative term representing the expected cost of } \\
\text { committing a larceny offense in } 1970\end{array}$ & .096 & .071 & .017 & .321 \\
\hline \multicolumn{6}{|c|}{ Socioeconc } \\
\hline \multicolumn{6}{|l|}{ mic } \\
\hline Nonwhite & $\begin{array}{l}\text { Percentage of the total state population that is nonwhite in } \\
1970\end{array}$ & 9.584 & 8.603 & .707 & 37.052 \\
\hline Unemploy & The percentage of labor force unemployed in 1970 & 4.494 & 1.005 & 3.200 & 7.900 \\
\hline
\end{tabular}


Table 3: Results of the Logistic Analyses for Robbery, Burglary, and Larceny in 1970

\begin{tabular}{|c|c|c|c|c|c|c|c|c|c|}
\hline \multirow[b]{2}{*}{ Variable } & \multicolumn{3}{|c|}{ Robbery } & \multicolumn{3}{|c|}{ Burglar } & \multicolumn{3}{|c|}{ Larcen } \\
\hline & $\begin{array}{l}\text { Decker and } \\
\text { Kohfeld } \\
\text { Model }\end{array}$ & $\begin{array}{c}\text { Alternative 1 } \\
\text { Model with } \\
\text { ExpCost }\end{array}$ & $\begin{array}{l}\text { Alternative 2 } \\
\text { Model with } \\
\text { ExpCost } \\
\text { operating } \\
\text { alone }\end{array}$ & $\begin{array}{l}\text { Decker and } \\
\text { Kohfeld } \\
\text { Model }\end{array}$ & $\begin{array}{l}\text { Alternative 1 } \\
\text { Model with } \\
\text { ExpCost }\end{array}$ & $\begin{array}{l}\text { Alternative 2 } \\
\text { Model with } \\
\text { ExpCost } \\
\text { operating } \\
\text { alone }\end{array}$ & $\begin{array}{l}\text { Decker and } \\
\text { Kohfeld } \\
\text { Model }\end{array}$ & $\begin{array}{c}\text { Alternative 1 } \\
\text { Model with } \\
\text { ExpCost }\end{array}$ & $\begin{array}{l}\text { Alternati } \\
\text { ve } 2 \\
\text { Model } \\
\text { with } \\
\text { ExpCost } \\
\text { operating } \\
\text { alone }\end{array}$ \\
\hline Intercept & $\begin{array}{l}-4.307 \\
(.974)^{*}\end{array}$ & $\begin{array}{c}-4.787 \\
(.782)^{*}\end{array}$ & $\begin{array}{c}-6.148 \\
(.716)^{*}\end{array}$ & $\begin{array}{c}-4.287 \\
(.507)^{*}\end{array}$ & $\begin{array}{c}-4.476 \\
(.459)^{*}\end{array}$ & $\begin{array}{c}-4.720 \\
(.283)^{*}\end{array}$ & $\begin{array}{c}-4.864 \\
(.526)^{*}\end{array}$ & $\begin{array}{c}-4.886 \\
(.497)^{*}\end{array}$ & $\begin{array}{r}-5.202 \\
(.357)^{*}\end{array}$ \\
\hline Clear & $\begin{array}{c}-.050 \\
(.022)^{*}\end{array}$ & $\begin{array}{c}-.052 \\
(.019)^{*}\end{array}$ & & $\begin{array}{r}.003 \\
(.017)\end{array}$ & $\begin{array}{r}.005 \\
(.016)\end{array}$ & & $\begin{array}{r}-.013 \\
(.021)\end{array}$ & \begin{tabular}{r|}
.014 \\
$(.021)$ \\
\end{tabular} & \\
\hline Conv|Off & $\begin{array}{c}-.098 \\
(.035)^{*}\end{array}$ & $\begin{array}{r}.008 \\
(.044)\end{array}$ & & $\begin{array}{c}-.550 \\
(.097)^{*}\end{array}$ & \begin{tabular}{r|}
-241 \\
$(.172)$
\end{tabular} & & $\begin{array}{c}-.485 \\
(.178)^{*}\end{array}$ & \begin{tabular}{r|}
.353 \\
$(.323)$ \\
\end{tabular} & \\
\hline Time & $\begin{array}{l}-0.010 \\
(.008)\end{array}$ & & & $\begin{array}{c}-0.005 \\
(.003)\end{array}$ & & & $\begin{array}{l}-0.001 \\
(.004)\end{array}$ & & \\
\hline ExpCost & & $\begin{array}{c}-.586 \\
(.019)^{*}\end{array}$ & $\begin{array}{c}-.731 \\
(.135)^{*}\end{array}$ & & $\begin{array}{r}-1.960 \\
(1.020)^{*}\end{array}$ & $\begin{array}{r}-3.252 \\
(.542)^{*}\end{array}$ & & \begin{tabular}{c|}
-1.021 \\
$(2.255)$
\end{tabular} & $\begin{array}{r}-2.918 \\
(1.156)^{*}\end{array}$ \\
\hline
\end{tabular}




\begin{tabular}{|c|c|c|c|c|c|c|c|c|c|}
\hline Nonwhite & $\begin{array}{r}.018 \\
(.016)\end{array}$ & $\begin{array}{r}.042 \\
(.016)^{*}\end{array}$ & $\begin{array}{r}.053 \\
(.017)^{*}\end{array}$ & $\begin{array}{r}.018 \\
(.007)^{*}\end{array}$ & $\begin{array}{r}.029 \\
(.009)^{*}\end{array}$ & $\begin{array}{r}.034 \\
(.008)^{*}\end{array}$ & $\begin{array}{r}-.007 \\
(.010)\end{array}$ & $\begin{array}{r}.009 \\
(.011)\end{array}$ & $\begin{array}{r}.006 \\
(.010)\end{array}$ \\
\hline Unemploy & $\begin{array}{r}-.126 \\
(.145)\end{array}$ & $\begin{array}{l}-.049 \\
(.131)\end{array}$ & $\begin{array}{l}-.085 \\
(.136)\end{array}$ & $\begin{array}{l}0.024 \\
(.059)\end{array}$ & $\begin{array}{r}.036 \\
(.058)\end{array}$ & $\begin{array}{r}.055 \\
(.056)\end{array}$ & $\begin{array}{r}.080 \\
(.076)\end{array}$ & $\begin{array}{r}.085 \\
(.077)\end{array}$ & $\begin{array}{r}.114 \\
(.073)\end{array}$ \\
\hline $\mathrm{N}$ & 31 & 31 & 31 & 32 & 32 & 32 & 31 & 31 & 31 \\
\hline $\mathrm{R}^{2}$ & .578 & .669 & .550 & .588 & .611 & .571 & .289 & .294 & .242 \\
\hline Adjusted $\mathrm{R}^{2}$ & .494 & .603 & .500 & .509 & .536 & .525 & .147 & .153 & .158 \\
\hline $\mathrm{S}_{\mathrm{e}}$ & .747 & .662 & .743 & .312 & .303 & .307 & .393 & .391 & .390 \\
\hline
\end{tabular}

Note: 1) The values in parentheses are the standard errors of the coefficients.

*Significant at the.05 level, one-tail test. 
Table 4: Results of the Logistic Analyses for Robbery, Burglary, and Larceny in 1970, with a Spuriousness Control

\begin{tabular}{|c|c|c|c|c|c|c|c|c|c|}
\hline \multirow[b]{2}{*}{ Variable } & \multicolumn{3}{|c|}{ Robbery } & \multicolumn{3}{|c|}{ Burglary } & \multicolumn{3}{|c|}{ Larceny } \\
\hline & $\begin{array}{l}\text { Decker and } \\
\text { Kohfeld } \\
\text { Model }\end{array}$ & $\begin{array}{c}\text { Alternative } 1 \\
\text { Model with } \\
\text { ExpCost }\end{array}$ & $\begin{array}{l}\text { Alternative } 2 \\
\text { Model with } \\
\text { ExpCost } \\
\text { operating } \\
\text { alone }\end{array}$ & $\begin{array}{c}\text { Decker and } \\
\text { Kohfeld } \\
\text { Model }\end{array}$ & $\begin{array}{c}\text { Alternative 1 } \\
\text { Model with } \\
\text { ExpCost }\end{array}$ & $\begin{array}{l}\text { Alternative } 2 \\
\text { Model with } \\
\text { ExpCost } \\
\text { operating } \\
\text { alone }\end{array}$ & $\begin{array}{l}\text { Decker and } \\
\text { Kohfeld } \\
\text { Model }\end{array}$ & $\begin{array}{c}\text { Alternative } 1 \\
\text { Model with } \\
\text { ExpCost }\end{array}$ & $\begin{array}{c}\text { Alternative 2 } \\
\text { Model with } \\
\text { ExpCost } \\
\text { operating } \\
\text { alone }\end{array}$ \\
\hline Intercept & $\begin{array}{l}-5.046 \\
(.749)^{*}\end{array}$ & $\begin{array}{l}-5.508 \\
(.603)^{*}\end{array}$ & $\begin{array}{l}-5.775 \\
(.465)^{*}\end{array}$ & $\begin{array}{l}-4.550 \\
(.413)^{*}\end{array}$ & $\begin{array}{l}-4.740 \\
(.384)^{*}\end{array}$ & $\begin{array}{r}-4.553 \\
(.231)^{*}\end{array}$ & $\begin{array}{l}-4.809 \\
(.459)^{*}\end{array}$ & $\begin{array}{l}-4.891 \\
(.435)^{*}\end{array}$ & $\begin{array}{l}-4.886 \\
(.317)^{*}\end{array}$ \\
\hline Clear & $\begin{array}{r}.007 \\
(.019)\end{array}$ & $\begin{array}{c}.012 \\
(.017)\end{array}$ & & $\begin{array}{r}.013 \\
(.014)\end{array}$ & $\begin{array}{l}.012 \\
(.014)\end{array}$ & & $\begin{array}{r}.002 \\
(.019)\end{array}$ & $\begin{array}{r}.002 \\
(.019)\end{array}$ & \\
\hline Conv $\mid$ Off & $\begin{array}{r}-.089 \\
(.027)^{*}\end{array}$ & $\begin{array}{l}.006 \\
(.033)\end{array}$ & & $\begin{array}{r}-.415 \\
(.085)^{*}\end{array}$ & $\begin{array}{r}-.164 \\
(.142)\end{array}$ & & $\begin{array}{r}-.326 \\
(.164)^{*}\end{array}$ & $\begin{array}{r}-.166 \\
(.290)\end{array}$ & \\
\hline Time & $\begin{array}{r}-.011 \\
(.006)^{*}\end{array}$ & & & $\begin{array}{r}-.005 \\
(.003)^{*}\end{array}$ & & & $\begin{array}{r}-. .002 \\
(.004)\end{array}$ & & \\
\hline ExpCost & & $\begin{array}{r}-.517 \\
(.145)^{*}\end{array}$ & $\begin{array}{r}-.518 \\
(.001)^{*}\end{array}$ & & $\begin{array}{l}-1.599 \\
(.844)^{*}\end{array}$ & $\begin{array}{r}-2.392 \\
(.486)^{*}\end{array}$ & & $\begin{array}{r}-1.140 \\
(1.972)\end{array}$ & $\begin{array}{r}-2.110 \\
(1.010)^{*}\end{array}$ \\
\hline Nonwhite & $\begin{array}{r}.002 \\
(.013)\end{array}$ & $\begin{array}{l}.021 \\
(.013)\end{array}$ & $\begin{array}{r}.021 \\
(.012)^{*}\end{array}$ & $\begin{array}{r}.006 \\
(.007)\end{array}$ & $\begin{array}{r}.015 \\
(.008)^{*}\end{array}$ & $\begin{array}{r}.017 \\
(.008)^{*}\end{array}$ & $\begin{array}{l}-. .006 \\
(.010)\end{array}$ & $\begin{array}{r}.004 \\
(.010)\end{array}$ & $\begin{array}{l}-.004 \\
(.009)\end{array}$ \\
\hline Unemploy & $\begin{array}{r}-.158 \\
(.110)\end{array}$ & $\begin{array}{c}.091 \\
(.098)\end{array}$ & $\begin{array}{c}. .105 \\
(.088)\end{array}$ & $\begin{array}{r}.048 \\
(.048)\end{array}$ & $\begin{array}{c}.058 \\
(.048)\end{array}$ & $\begin{array}{l}.056 \\
(.045)\end{array}$ & $\begin{array}{l}.088 \\
(.067)\end{array}$ & $\begin{array}{r}.094 \\
(.067)\end{array}$ & $\begin{array}{r}.098 \\
(.062)\end{array}$ \\
\hline $1 /$ Offn & $\begin{array}{c}-114.651 \\
(25.864)^{*}\end{array}$ & $\begin{array}{c}-103.934 \\
(22.642)^{*}\end{array}$ & $\begin{array}{c}-113.159 \\
(18.127)^{*}\end{array}$ & $\begin{array}{c}-1617.647 \\
(414.116)^{*}\end{array}$ & $\begin{array}{l}-1522.300 \\
(414.044)^{*}\end{array}$ & $\begin{array}{l}-1513.525 \\
(375.868)^{*}\end{array}$ & $\begin{array}{c}-1887.138 \\
(631.384)^{*}\end{array}$ & $\begin{array}{c}-1844.899 \\
(625.617)^{*}\end{array}$ & $\begin{array}{r}-1907.795 \\
(563.029)^{*}\end{array}$ \\
\hline $\mathrm{N}$ & 31 & 31 & 31 & 32 & 32 & 32 & 31 & 31 & 31 \\
\hline $\mathrm{R}^{2}$ & .768 & .824 & .820 & .744 & .748 & .732 & .482 & .482 & .475 \\
\hline Adjusted $\mathrm{R}^{2}$ & .710 & .780 & .792 & .683 & .687 & .692 & .352 & .352 & .394 \\
\hline$\overline{S_{e}}$ & .566 & .493 & .479 & .251 & .249 & .247 & .342 & .342 & .331 \\
\hline
\end{tabular}

Note: 1) The values in parentheses are the standard errors of the coefficients.

*Significant at the .05 level, one-tail test. 
Table 5: Results of the Log-Linear and Semi-logarithmic Models for Robbery, Burglary, and Larceny in 1970

\begin{tabular}{|c|c|c|c|c|c|c|c|c|c|}
\hline \multirow[b]{2}{*}{ Variable } & \multicolumn{3}{|c|}{ Robbery } & \multicolumn{3}{|c|}{ Burglary } & \multicolumn{3}{|c|}{ Larceny } \\
\hline & $\begin{array}{r}\text { Lin-log } \\
\text { Model }\end{array}$ & Log-lin Model & $\begin{array}{c}\text { Log-linear } \\
\text { Model }\end{array}$ & $\begin{array}{c}\text { Lin-log } \\
\text { Model }\end{array}$ & $\begin{array}{c}\text { Log-lin } \\
\text { Model }\end{array}$ & $\begin{array}{c}\text { Log-linear } \\
\text { Model }\end{array}$ & $\begin{array}{c}\text { Lin-log } \\
\text { Model }\end{array}$ & $\begin{array}{c}\text { Log-lin } \\
\text { Model }\end{array}$ & $\begin{array}{l}\text { Log-linear } \\
\text { Model }\end{array}$ \\
\hline Intercept & $\begin{array}{r}1406.300 \\
(235.636)^{*}\end{array}$ & $\begin{array}{r}8.073 \\
(.938)^{*}\end{array}$ & $\begin{array}{r}15.302 \\
(2.351)^{*}\end{array}$ & $\begin{array}{r}2198.574 \\
(1005.871)^{*}\end{array}$ & $\begin{array}{r}7.748 \\
(.529)^{*}\end{array}$ & $\begin{array}{r}9.289 \\
(1.265)^{*}\end{array}$ & $\begin{array}{l}1368.281 \\
(816.760)\end{array}$ & $\begin{array}{r}6.723 \\
(.570)^{*}\end{array}$ & $\begin{array}{r}7.603 \\
(1.199)^{*}\end{array}$ \\
\hline Clear & $\begin{array}{c}-185.761 \\
(53.754)^{*}\end{array}$ & $\begin{array}{r}-.066 \\
(.018)^{*}\end{array}$ & $\begin{array}{l}-1.871 \\
(.536)^{*}\end{array}$ & $\begin{array}{r}-271.880 \\
(250.217)\end{array}$ & $\begin{array}{r}-.032 \\
(.017)^{*}\end{array}$ & $\begin{array}{l}-. .518 \\
(.315)\end{array}$ & $\begin{array}{r}-385.014 \\
(202.251)^{*}\end{array}$ & $\begin{array}{l}.022 \\
(.024)\end{array}$ & $\begin{array}{r}-.532 \\
(.297)^{*}\end{array}$ \\
\hline Conv| Arr & $\begin{array}{c}-100.183 \\
(20.574)^{*}\end{array}$ & $\begin{array}{l}-.048 \\
(.013)^{*}\end{array}$ & $\begin{array}{r}-.963 \\
(.205)^{*}\end{array}$ & $\begin{array}{c}-411.768 \\
(69.041)^{*}\end{array}$ & $\begin{array}{r}-.106 \\
(.020)^{*}\end{array}$ & $\begin{array}{r}-.467 \\
(.087)^{*}\end{array}$ & $\begin{array}{c}-211.385 \\
(67.672)^{*}\end{array}$ & $\begin{array}{r}-.037 \\
(.018)^{*}\end{array}$ & $\begin{array}{r}-.289 \\
(.099)^{*}\end{array}$ \\
\hline Time & $\begin{array}{c}-107.931 \\
(27.923)^{*}\end{array}$ & $\begin{array}{c}.013 \\
(.007)^{*}\end{array}$ & $\begin{array}{r}-0.676 \\
(.279)^{*}\end{array}$ & $\begin{array}{r}-247.624 \\
(111.399)^{*}\end{array}$ & $\begin{array}{c}-.006 \\
(.004)\end{array}$ & $\begin{array}{r}-.310 \\
(.140)^{*}\end{array}$ & $\begin{array}{r}-72.843 \\
(110.626)\end{array}$ & $\begin{array}{r}-.000 \\
(.005)\end{array}$ & $\begin{array}{r}.090 \\
(.162)\end{array}$ \\
\hline Nonwhite & $\begin{array}{r}29.634 \\
(12.666)^{*}\end{array}$ & $\begin{array}{r}.023 \\
(.015)\end{array}$ & $\begin{array}{r}.436 \\
(.126)^{*}\end{array}$ & $\begin{array}{r}187.359 \\
(49.175)^{*}\end{array}$ & $\begin{array}{r}.020 \\
(.007)^{*}\end{array}$ & $\begin{array}{r}.212 \\
(.062)^{*}\end{array}$ & $\begin{array}{r}137.818 \\
(56.625)^{*}\end{array}$ & $\begin{array}{r}.003 \\
(.010)\end{array}$ & $\begin{array}{r}.184 \\
(.083)^{*}\end{array}$ \\
\hline Unemploy & $\begin{array}{r}-47.978 \\
(57.673)\end{array}$ & $\begin{array}{l}-.139 \\
(.134)\end{array}$ & $\begin{array}{r}-.963 \\
(.205)^{*}\end{array}$ & $\begin{array}{r}337.710 \\
(225.411)\end{array}$ & $\begin{array}{c}.027 \\
(.060)\end{array}$ & $\begin{array}{r}.117 \\
(.284)\end{array}$ & $\begin{array}{r}402.313 \\
(256.273)\end{array}$ & $\begin{array}{r}.072 \\
(.080)\end{array}$ & $\begin{array}{r}.401 \\
(.376)\end{array}$ \\
\hline $\mathrm{N}$ & 31 & 31 & 31 & 32 & 32 & 32 & 31 & 31 & 31 \\
\hline $\mathrm{R}^{2}$ & .714 & .635 & .742 & .644 & .564 & .596 & .404 & .215 & .352 \\
\hline Adjusted $\mathrm{R}^{2}$ & .657 & .563 & .690 & .576 & .480 & .518 & .285 & .058 & .223 \\
\hline $\mathrm{S}_{\mathrm{e}}$ & 58.605 & .695 & .585 & 243.705 & .319 & .307 & 253.505 & .410 & .372 \\
\hline
\end{tabular}

Note: 1) The values in parentheses are the standard errors of the coefficients.

*Significant at the .05 level, one-tail test. 


\section{Figure 1: Crime Rates per 100,000 Population Predicted from the Expected Cost of Committing the Crime, by Type of Crime}

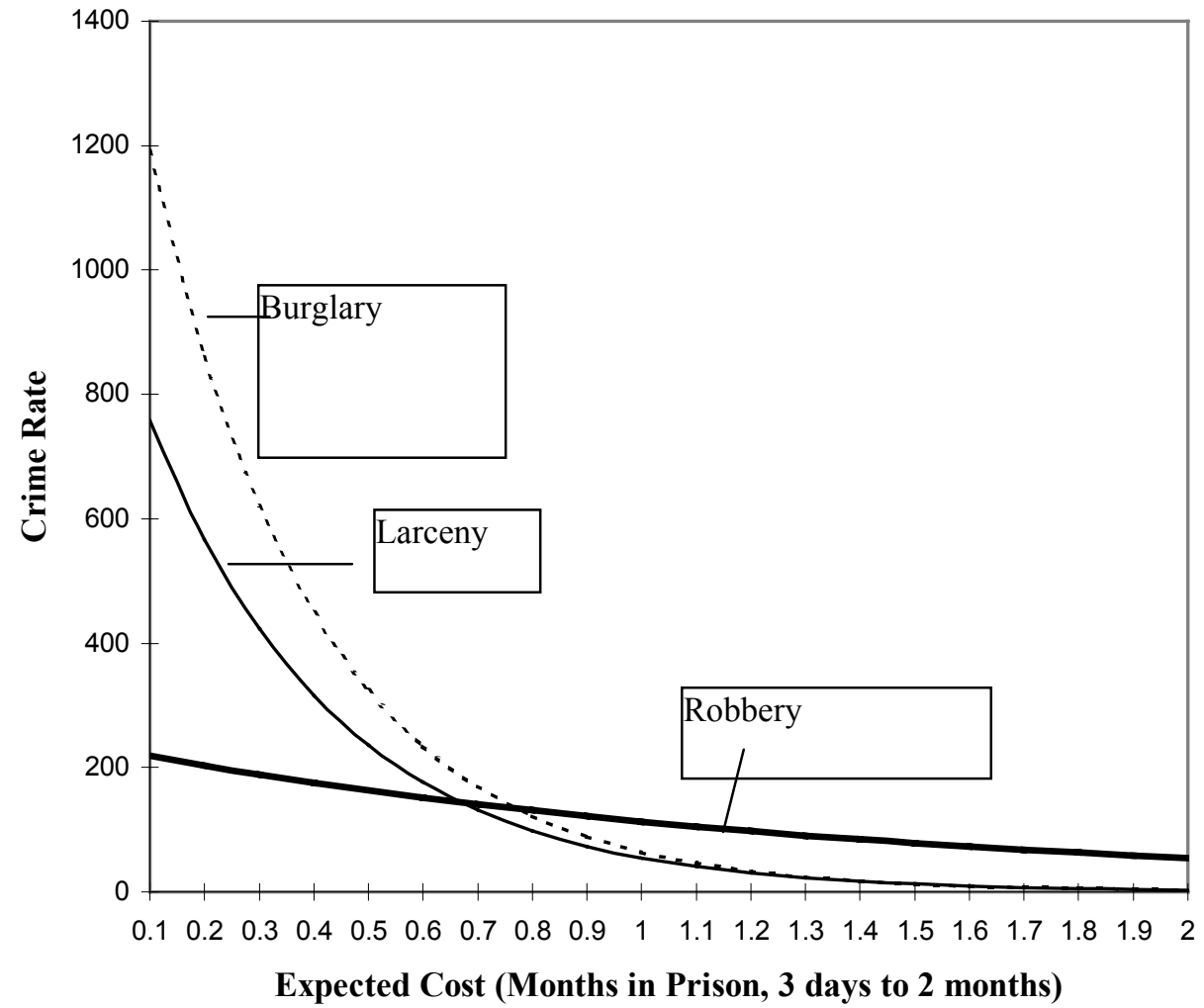

Note: Estimates are based on equations referred to as "Model with ExpCost operating alone" reported in Table 3. All estimates assume a 10\% nonwhite population and a 5\% unemployment rate.

\footnotetext{
${ }^{1}$ Celerity, despite its interesting properties and despite interesting recent research on time horizons in decision making (Nagin \& Pogarsky 2000), is not a core component of deterrence theory as such. Celerity was a part of the Beccarian and Benthamite argument, which also included the core deterrence components of certainty and severity. For that reason, most accounts of Classical theory of crime will mention celerity in passing, but not much more. For example, Charles Tittle $(1980,8)$ wrote, "The original utilitarian thinkers emphasized three sanction traits - certainty, severity, and celerity-and modern scholars have continued to focus on the certainty and severity of sanctions although few have considered celerity to be of much import except in the context of operant conditioning."

One could make an argument for excluding celerity on empirical grounds, as Robert Chauncey $(1975,450-1)$ has when he argued that "...celerity ...has generally been omitted from detailed consideration for two reasons. First, long delays generally are not disadvantageous to the offender, as bail is usually available. Second, celerity tends to become intertwined with both certainty and severity, as long delays are associated with complex defense maneuvers, nonavailability of witnesses, and increased prosecution willingness to plea bargain. Thus the major emphasis of the literature has centered on the attempt to distinguish the deterrent effects of severity from the effects of certainty." However, there are theoretical reasons for not treating celerity as a core component of deterrence. Jack Gibbs said it best $(1975,130)$ when he wrote: "Although Beccaria and Bentham emphasized the importance of the celeritous punishment,
} 
celerity is the most debatable variable in the deterrence doctrine. The only rationale for an emphasis on celerity is found in experimental psychology... Since legal punishments (even procedural) are commonly delayed for days if not months or years, it is difficult to see how experimental findings support the assumption that differences among jurisdictions or types of crime can be attributed even in part to contrasts in the celerity of punishment. In any case, one would surely be pressed to argue that the importance of the celerity extends beyond specific deterrence."

${ }^{2}$ Andrew von Hirsch and his colleagues promote an opposing view (von Hirsch et al., 1999). They argue that it is essential for analysts to consider the certainty and severity components separately, because it may be that one rather than both components produces the deterrent effect. We endorse the wisdom of distinguishing between the possible weights that the certainty and severity elements may carry. See our results and the text surrounding Table 5. However, our position is that the components must be considered as a theoretical unit and cannot be treated as independent forces that, operating alone, could deter anything.

${ }^{3}$ About roughly the same time, correlational and frequency analyses incorporating this idea were introduced in the sociological literature (Chambliss, 1966; Gibbs, 1968; Tittle, 1969, Logan, 1972).

${ }^{4}$ Commentators have suggested that the logistic form is inherently interactive. It is not (see Frant, 1991, commenting on Berry \& Berry's mistaken interaction interpretation of logistic regression). The mistaken interpretation applies a linear model definition of interaction - i.e., that the rate of change in the translation of $\mathrm{X}$ into $\mathrm{Y}$ depends on the level of a third variable - to the logistic results, when those results are displayed as nonlinear probabilities as opposed to log odds. That misconstrues the nonlinear logit translation of $\mathrm{X}$ into $\mathrm{Y}$, expressed as probabilities, with an interactive translation of $\mathrm{X}$ into $\mathrm{Y}$. In logistic regression, or any $\log$ form of $\mathrm{Y}$ for that matter, the curve by which $\mathrm{X}$ translates into $\mathrm{Y}$ shifts left or right depending on the level of a third (fourth, or more) variable, but the functional form of that translation is unaffected. The single most important fact about the interaction that we are making should be easy to understand at the extreme. Deterrence specifies that arrest, conviction, and severity of punishment are individually necessary elements. We are pointing out what sometimes seems to be forgotten; none of these elements is sufficient when operating alone. By implication, if the value of any one of the elements is zero, there is no deterrence because the effect of the other two elements falls to zero. The logistic form, absent the interaction, says no such thing. Rather, it says that as long as any one element and that element's coefficient are nonzero, then a deterrent effect is produced by virtue of that element operating alone, regardless of the values of the other elements.

${ }^{5}$ Despite the dated time period of the Pogue data, these data are, to the best of our knowledge, the only existing crossjurisdictional account of the time served in prison. Having that information is essential to our analysis. Therefore, although more recent data are preferred, for the purpose of testing our central proposition, the time period is not an especially relevant matter. The relationship should hold irrespective of the particular year we use. They are also official crime data and, as with all criminal data, self-reported included, the reader should be wary of the limitations inherent to these data.

${ }^{6}$ Due to missing data, the analyses cover 31 or 32 states. Excluded from all analyses are: Alabama, Alaska, Arkansas, Florida, Hawaii, Indiana, Iowa, Louisiana, Michigan, Nebraska, New Jersey, North Carolina, Oregon, Pennsylvania, Rhode Island, Texas, Virginia, and Wisconsin. Vermont is missing from the robbery and larceny analyses.

${ }^{7}$ We are also concerned with the potential simultaneous relationship between each of the deterrent variables and the dependent variable. One approach to avoiding a direct form of simultaneity between the 1970 crime rate and the 1970 deterrence variables, is to re-estimate the equations in Table 3 using values of the deterrence variables from a previous year. We find that regressing the crime rates in 1971 onto the certainty and severity of punishment variables in 1970 allows us to make the same inferences that we drew from the results in Table 3. In this way, this form of direct simultaneity is not an issue in our analysis. No evidence of a deterrent effect of the severity of punishment is found with the Decker \& Kohfeld model. Only the certainty of punishment, through the probability of imprisonment for all three crimes and the clearance rate for robbery, has a significant deterrent effect on the crime rate. The expected cost continues to be significantly inversely related to robbery and burglary but not to larceny using Alternative 1 and to all three crime rates using Alternative 2. In addition, moving from the original Decker \& Kohfeld model to our Alternative 1 continues to improve the overall fit.

${ }^{8}$ Other statistical doubts may exist for readers. We have checked these as well. One is multicollinearity. Observational designs often make one wonder whether inferences drawn from an analysis are plagued by doubts that arise from a multicollinearity problem. Doubts resting on inter-correlated independent variables are even more so the case when an equation includes an interaction variable formed by the multiplication of other elements that also stand on their own in the equation (i.e., so-called main effects). We have checked the inter-correlation of our variables, and, as one would expect, clearance and convictions rates are more highly correlated with the other independent variables in the equations when the 
interaction is present. Does that, as such, indicate that the results suffer from a multicollinearity problem? No. Multiple regression is used to overcome inferential problems arising due to correlated independent variables; if the correlation did not exist, there would be little need for anything beyond bivariate analysis. The problem of multicollinearity exists when increased inter-correlation is not offset by a reduction in the standard error of estimate. When there is no offsetting, the standard error of one of more independent variables is inflated and we become uncertain, perhaps highly so, about the size of the estimated effect(s). As one can see in Table 4, the standard error of estimate values are lower when the interactions are included than when they are not. Moreover, the coefficients' standard errors show little and, sometimes, no sign of inflation. And finally, as we shall show in Table 5 below, when the log-linear model is estimated, the severity variable is statistically significant. Of course, in that model form, it is not plausible to believe that multicollinearity caused most or all of the deterrence components to be significant. The evidence is clear. The inclusion of the expected cost interaction variable tends to partial out the effects of clearance and conviction rates standing alone, as deterrence theory asserts.

We have also probed the residuals for signs of heteroscedasticty. One can see from the descriptive statistics in Table 1 that the crime rate variables are skewed positively. The maximum values are more distant from their respective mean compared to the minimum values. The skew could create doubts associated with outliers or from heteroscedasticity. We have no substantial evidence that causes a worry on these scores. Without going into a full-fledged and detailed recounting of the evidence, the convincing results on this regard are provided in Table 5 below in the form of the results from the log-linear model.

${ }^{9}$ We extended our testing of the proposition that the three deterrence elements come together to form and operate as a single expected cost term. For instance, the timed served variable in the semi-log and even the log-linear equations in Table 5 could be replaced by a single expected cost variable. When that adjustment is made, the evidence on robbery and burglary tends to support the use of the expected cost variable. None of the deterrence terms reach statistical significance for larceny. The single expected cost variable is statistically significant in all three equations forms for robbery and burglary. The conviction rate variable is never significant. The clearance rate variable is significant for the log-lin and log-linear versions of the robbery equation but not for any of the three burglary equations. 